\title{
Priming of NK cell anti-viral effector mechanisms by direct recognition of human cytomegalovirus
}

\author{
Aura Muntasell ${ }^{1}$, Marcel Costa-Garcia ${ }^{2}$, Andrea Vera ${ }^{1}$, Noemí Marina-Garcia $^{2}$, Carsten J. Kirschning ${ }^{3}$ and \\ Miguel López-Botet ${ }^{1,2}$
}

\author{
${ }^{1}$ Hospital del Mar Medical Research Institute, Barcelona, Spain \\ 2 Immunology Unit, Pompeu Fabra University, Barcelona, Spain \\ ${ }^{3}$ Institute of Medical Microbiology, University of Duisburg-Essen, Essen, Germany
}

Edited by:

Eric Vivier, Centre d'Immunologie de

Marseille-Luminy, France

Reviewed by:

Eric Vivier, Centre d'Immunologie de

Marseille-Luminy, France

Laurel L. Lenz, National Jewish

Health, USA

Hugh Reyburn, Spanish National

Research Council, Spain

*Correspondence:

Aura Muntasell, Laboratory of

Immunity and Infection, Hospital del

Mar Medical Research Institute, Dr.

Aiguader, 88, 08003 Barcelona, Spain.

e-mail: amuntasell@imim.es
Natural killer (NK) cells play an important role in the defense against viral infections. Activation of resting NK cells is tightly controlled by the balance of surface inhibitory and activating receptors and aided by cytokines released by accessory cells along the anti-viral response. On the other hand, NK cells express functional pattern recognition receptors (PRRs) whose function has been mostly addressed by the use of synthetic agonists. The present study was undertaken to investigate whether NK cells could directly recognize a complex pathogen such as Human Cytomegalovirus (HCMV). Exposure of primary human NK cells to HCMV (TB40/E strain) induced the expression of CD69, promoted IFN $\gamma$ secretion, and increased their cytotoxic activity against HCMV-infected autologous monocyte-derived dendritic cells. The divergent response induced by infective and UVinactivated virions indicated the involvement of different NK cell sensors in the recognition of HCMV. The fact that NK cell activation could be partially prevented by blocking mAb specific for IFNAR and TLR2, together with the induction of IFN $\beta$ mRNA, supported the involvement of IFN $\beta$ and TLR2 in the response to HCMV. Thus, our data indicate that simultaneous activation of several PRRs leads to the autonomous priming of NK cell effector functions and could be a previously unappreciated mechanism presumably contributing to the control of HCMV infection.

Keywords: NK cells, HCMV, pathogen-associated pattern recognition receptors

\section{INTRODUCTION}

Natural killer (NK) cells provide an important first line of defense against viral pathogens. NK cells participate in the viral clearance by lysing infected cells and through the production of IFN $\gamma$ and TNF $\alpha$ which exert a non-cytolytic control of the infection and modulate the induction of protective specific responses. Activation of NK cells is tightly controlled by the balance between germ-line encoded inhibitory and activating receptors (Lanier, 2008) and modulated by the action of innate cytokines (Biron et al., 1999). More recently, a role for pathogen-associated pattern recognition receptors (PRRs) as regulators of the NK cell biology has emerged. Initial studies based on mRNA detection on human NK cell extracts, described TLR1 as the highest expressed, followed by moderate levels of TLR2, TLR3, TLR5, and TLR6, and low levels of TLR4, TLR7, TLR8, and TLR9 mRNA (Hornung et al., 2002; Chalifour et al., 2004; Hart et al., 2005; Gorski et al., 2006; Marcenaro et al., 2008). TLR2, TLR3, TLR7, and TLR9 have been shown to be intracellular in human NK cells (Roda et al., 2005; Eriksson et al., 2006; Girart et al., 2007; Marcenaro et al., 2008), although surface expression has also been reported for TLR2 and TLR3 (Becker et al., 2003; Hart et al., 2005). Generally, exposure of primary NK cells to individual synthetic Toll-like receptor (TLR) agonists did not enhance NK cell effector functions unless combined with cytokines such as IL-12 or type I IFNs, yet conflicting data can also be found (Sivori et al., 2004; Hart et al., 2005;
Roda et al., 2005; Eriksson et al., 2006; Girart et al., 2007; Duluc et al., 2009). Activation of TLR2, TLR7/8 promotes the secretion of IFN $\gamma$ while having little effect in NK cell cytotoxic responses (Hart et al., 2005; Girart et al., 2007); in contrast, TLR9 signaling induces the expression of activation markers and enhances $\mathrm{Ab}$ dependent cytotoxicity (Hornung et al., 2002; Sivori et al., 2004; Roda et al., 2005; Girart et al., 2007). One of the strongest agonist for NK cell function is polyI:C which in combination with IL-2 or IL-12 promotes both IFN $\gamma$ and cytotoxic responses through the secretion of IFN $\beta$ (Sivori et al., 2004; Hart et al., 2005; Girart et al., 2007; Duluc et al., 2009). Recently, sensing of poly I:C in NK cells has been shown to mostly depend on RIG-1-like receptors (Perrot et al., 2010), introducing cytosolic PRRs in the regulation of NK cell biology. Indeed, NK cells express functional NOD-2, NRLP3, Mda5, and RIG-1(Athie-Morales et al., 2008; Duluc et al., 2009; Perrot et al., 2010).

To date, few studies have addressed the consequences of pathogen sensing by NK cells. Interaction of human NK cells with Mycobacterium bovis involved TLR2 and triggered NK cell activation (Marcenaro et al., 2008). NK cells have been shown to exhibit direct microbicidal activity against Cryptococcus neoformans (Marr et al., 2009). Remarkably, direct recognition of vaccinia virus by TLR2 in NK cells was necessary for the efficient control of this infection in a murine model, highlighting the importance of NK cell pathogen recognition in vivo (Martinez et al., 2010). 
The contribution of NK cells in the immune response to viruses is evidenced by the fact that patients with NK cell deficiencies are susceptible to recurrent herpesviral infections, including Human Cytomegalovirus (HCMV; Biron et al., 1989; Orange and Ballas, 2006). HCMV is an enveloped dsDNA virus which in vitro can productively infect fibroblasts and, less efficiently, endothelial, and differentiated myelomonocytic cells (Mocarski and Courcelle, 2001). Cytomegalovirus infection activates the innate immune system through both TLR-dependent and -independent pathways. Mice strains harboring specific deletions evidenced the participation of TLR2 and TLR9 in the recognition of MCMV envelope glycoproteins and viral DNA, respectively (Krug et al., 2004; Tabeta et al., 2004; Szomolanyi-Tsuda et al., 2006; Zucchini et al., 2008). TLR3 and TLR7 are also involved in sensing CMV (Tabeta et al., 2004; Zucchini et al., 2008) although it is not clear whether they are activated during initial infection or later during the viral replication cycle. In humans, HCMV glycoproteins gB and gH activate TLR2 signaling (Boehme et al., 2006). CMV also stimulates cytosolic DNA sensors such as DAI/ZBP1 in human fibroblasts (DeFilippis et al., 2010) and the AIM2 inflammasome along MCMV infection (Rathinam et al., 2010). Epidemiological data also supports the involvement of TLR2 and TLR9 in HCMV sensing. Three genetic studies have identified specific single nucleotide polymorphisms in TLR2 and TLR9 genes which are highly predictive of susceptibility to HCMV infection/reactivation in adult recipients of liver and allogeneic stem cell transplants, respectively (Kijpittayarit et al., 2007; Carvalho et al., 2009; Kang et al., 2012).

The present study was undertaken to investigate the consequences of the direct interaction between NK cells and a complex pathogen such as HCMV. We provide data supporting the capacity of NK cells to directly sense HCMV, identifying some of the mechanisms underlying this process, and dissecting the consequences of this interaction on NK cell function. Our results support that the simultaneous engagement of different PRRs on NK cells by HCMV leads to an accessory cell-independent enhancement of NK cell effector mechanisms, likely contributing to the development of an efficient response against the infection.

\section{MATERIALS AND METHODS}

\section{ANTIBODIES AND FLOW CYTOMETRY ANALYSIS}

FACS analysis was performed using monoclonal antibodies specific for the following surface molecules: CD56-allophycocyanin (APC), CD3-Phycoerythrin (PE), CD19-PE, CD123-PE, CD14$\mathrm{PE}, \mathrm{CD} 1 \mathrm{a}-\mathrm{PE}, \mathrm{CD} 69-\mathrm{PE}, \mathrm{IFN} \gamma-\mathrm{PE}, \mathrm{CD} 107 \mathrm{a}-$ fluorescein isothiocyanate (FITC; BD Biosciences Pharmingen, San Diego, CA, USA). Anti-NKp30 (clone AZ20), and -NKp46 (clone BAB281) mAbs were kindly provided by Prof. A. Moretta (University of Genova, Italy). MAb anti-CD16 (clone KD1) has been previously described. Cells were pretreated with human aggregated IgG $(10 \mu \mathrm{g} / \mathrm{ml})$ to block Fc receptors, and subsequently labeled with specific antibodies. Cell viability was measured using the FITC Annexin V Apoptosis Detection Kit II (BD Pharmingen, San Diego, CA, USA) according to the manufacturer's instructions.

For blocking experiments the following monoclonal antibodies were used at saturating concentrations: antagonistic mAb specific for TLR2 (clone T2.5; Meng et al., 2004) was kindly provided by Dr. Carsten Kirschning (Institute of Medical Microbiology, University of Duisburg-Essen, Essen, Germany). Blocking antibody against IFN receptor chain 2 (IFNAR; clone MMHAR-2, IgG2a) was from Calbiochem. An anti-myc mAb (9E10, IgG1) was used as negative control.

\section{NK CELL ISOLATION}

PBMC were obtained from heparinized blood samples by separation on Ficoll-Hypaque gradient (Lymphoprep; Axis-Shield PoC AS, Oslo, Norway). Samples were obtained with the informed consent of the subjects and the study protocol was approved by the institutional Ethics Committee (CEIC-IMAS). NK cell purification was performed by negative selection using EasySep Human NK Cell Enrichment kit (StemCell Technologies, Grenoble, France) according to the manufacturer's recommendations.

\section{HCMV PREPARATION AND NK CELL TREATMENT}

Purified stocks of HCMV TB40/E strain (Sinzger et al., 1999; kindly provided by Dr. Christian Sinzger, Institute for Medical Virology, University of Tubingen, Tubingen, Germany) were prepared as previously described (Muntasell et al., 2010). Briefly, MRC-5 cells were infected at 0.1 moi and supernatants recovered when maximum cytopathic effect was reached. Virus was pelleted twice through a sorbitol cushion $(20 \% \mathrm{D}$-sorbitol in TBS ( $25 \mathrm{mM}$ Tris- $\mathrm{HCl}, \mathrm{pH} 7.4,137 \mathrm{mM} \mathrm{NaCl}$ ) by centrifugation $90 \mathrm{~min}$ at $27,000 \times g$ at $15^{\circ} \mathrm{C}$, resuspended in serum-free DMEM, and titered by standard plaque assays on MRC- 5 cells. Inactivation of viral stocks was achieved by UV-light using an UV-crosslinker (Biorad GS genelinker UV chamber). A fraction of viral stocks was passed through $0.1 \mu \mathrm{m}$ filter to eliminate viral particles. Viral UVlight inactivation and the absence of infectious virus in filtered viral stocks were confirmed by treating the MRC-5 fibroblast cell line with the viral preparations, followed by detection of the viral IE-1/IE-2 antigen with a mouse anti-CMV mAb (clone mab810, Millipore). No infected cells could be detected in MRC-5 monolayers incubated with UV-inactivated TB40/E or filtered viral stocks. In contrast, IE-1 nuclear staining was observed in 100\% of MRC-5 cells treated with TB40/E.

Isolated NK cells were cultured in complete RPMI medium supplemented with $200 \mu / \mathrm{ml}$ rhIL-2 (unless noted in the figure) in the presence or absence of HCMV TB40/E strain (moi 5-10, based on NK cell number), and CD69 expression was monitored after $24 \mathrm{~h}$ by flow cytometry. For inhibition of TLR-two-dependent and type I IFN-dependent activity, NK cells were incubated with an anti-TLR2 Ab (T2.5), anti-IFNAR Ab (MMHAR-2), or a control $\mathrm{Ab}$ for $1 \mathrm{~h}$ before the addition of HCMV. Inhibition of endosomal maturation was achieved by treating NK cells with Bafilomycin A1 ( $25 \mathrm{nM}$; Sigma, Saint Louis, MO, USA) for $30 \mathrm{~min}$ before HCMV addition and during the $8 \mathrm{~h}$ of co-culture.

\section{FUNCTIONAL ASSAYS}

Supernatants of non-treated or HCMV-exposed NK cells were collected after 24 and $48 \mathrm{~h}$ and frozen at $-80^{\circ} \mathrm{C}$. Thawed samples were assayed by ELISA for IFN $\gamma$ and IFN $\alpha$ (Bender MedSystems, Vienna, Austria).

Natural killer cell degranulation was measured by the CD107a mobilization assay (Alter et al., 2004). NK cells were non-treated or exposed to HCMV TB40/E strain. After $24 \mathrm{~h}$ NK cells were harvested, washed and incubated with $1 \mu \mathrm{g}$ anti-CD107a-FITC and 
$5 \mathrm{ng} / \mathrm{ml}$ monensin for $4 \mathrm{~h}$ at $37^{\circ} \mathrm{C}$ with $10 \% \mathrm{CO}_{2}$, either alone or in the presence of autologous $\mathrm{HCMV}$-infected monocyte-derived Dendritic Cells (moDC) or the K562 erythroleukemia cell line. P815 murine mastocytoma cell line was pre-incubated with antiNKp46, anti-NKp30, and anti-CD16 mAb, and used as target in redirected degranulation assays. After co-culture, cells were stained with anti-CD56 mAb and analyzed by flow cytometry.

MoDCs were generated as described previously (Magri et al., 2011). After 5 days, cells were infected with HCMV TB40/E strain (moi 50-100). At $48 \mathrm{~h}$ post-infection DC were harvested and used as targets cells in degranulation assays. To monitor the infection rate, cells were washed twice and cytospin preparations were stained by indirect immunofluorescence with a mouse antiCMV IE-1/IE-2 monoclonal antibody (clone mab810, Chemicon, Temecula, CA, USA).

\section{MEASUREMENT OF mRNA LEVELS}

For RNA and cDNA preparation, NK cells $\left(2 \times 10^{6}\right)$ were isolated by negative selection and exposed to TB40/E HCMV strain (moi 5$10)$ in combination with IL-12 (10 ng/ml) for 6 and $12 \mathrm{~h}$. Cells were lysed in RLT buffer (300 $\mu$ l, RNeasy system, QIAGEN, 74104) and total RNA was isolated using the same system. RNA was quantified in a NanoDrop ${ }^{\circledR}(\mathrm{ND}-1000$ Spectrophotometer) and $250 \mathrm{ng}$ were retro-transcribed to cDNA using SuperScript III reverse transcriptase and random primers (Invitrogen). For real-time quantitative PCR (RT-qPCR), LightCycler 480 SYBR Green I Master (Roche) and a Roche LightCycler 480 detection system (Roche) were used following the instructions provided by the manufacturers. Samples were normalized to GAPDH mRNA levels using the LightCycler 480 Software, version 1.5. Primer sequences for the PCR reactions were: $5^{\prime}$-GCC ATC AAT GAC CCC TTC ATT-3' (Forward) and 5'-TTG ACG GTG CCA TGG AAT TT-3' (Reverse) for GAPDH; 5' -AAA CTC ATG AGC AGT CTG CA-3' (Forward) and 5'-AGG
AGA TCT TCA GTT TCG GAG G-3' (Reverse) for IFN $\beta$ (DeFilippis et al., 2010); 5'-GCA GGT CAT TCA GAT GTA GCG G-3' (Forward) and $5^{\prime}$-TGT CTT CCT TGA TGG TCT CCA CAC-3' (Reverse) for IFN $\gamma$ (Janson et al., 2008).

\section{STATISTICAL ANALYSIS}

Statistical analysis was performed by the Student $t$-test using GraphPad Prism 5 software. Results were considered significant at the two-sided $P$ level of 0.05 .

\section{RESULTS \\ DIRECT RECOGNITION OF HCMV BY NK CELLS INDUCES CD69 EXPRESSION AND SYNERGIZES WITH IL-12 IN THE PRODUCTION OF IFN $\gamma$}

To assess whether NK cells could directly recognize HCMV we set up an experimental culture system including highly purified primary NK cells and viral particles of the TB40/E HCMV viral strain. Purity of the NK cells obtained was $>98 \%$ as evaluated by flow cytometry including an anti-CD56 as an NK cell marker against a panel of mAbs including anti-CD19, -CD14, -CD3, -CD1a, and -CD123 as lineage exclusion cocktail (Figure 1A). In all experiments, NK cells were stimulated with 5-10 infective viral particles per cell (from now on referred as HCMV moi). We initially monitored the up-regulation of the early activation marker CD69 by flow cytometry and the production of IFN $\gamma$ in cell-free supernatants by ELISA. IL-12 (10 ng/ml) was added to promote IFN $\gamma$ production. After $24 \mathrm{~h}, \mathrm{HCMV}$ and IL-12, alone or in combination, induced the expression of CD69 on NK cells (Figure 1B). HCMVinduced expression of CD69 was mostly restricted to CD56 $6^{\mathrm{dim}}$ NK cells, at variance with the general up-regulation induced by IL-12 treatment. On the other hand, incubation of NK cells with HCMV resulted in a modest production of IFN $\gamma$, but significantly enhanced the secretion induced by IL-12, as measured by ELISA in the cell-free supernatant after 24 and $48 \mathrm{~h}$ (Figure 1C).
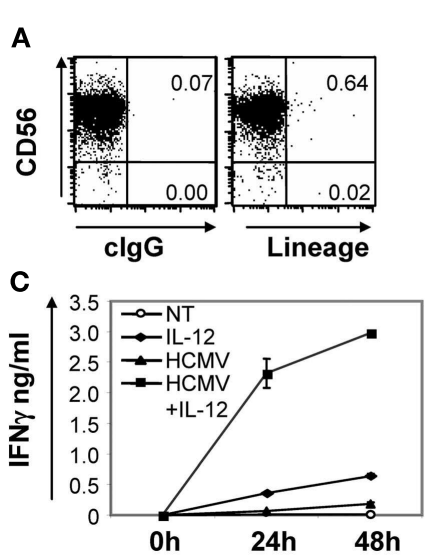

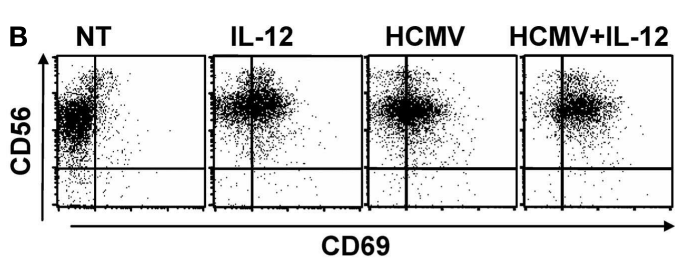

D

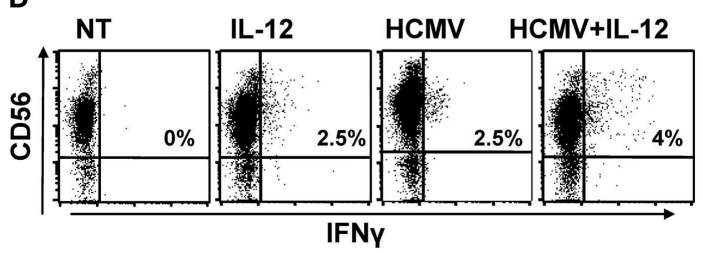

FIGURE 1 | Direct HCMV recognition induced CD69 expression in NK cells and enhanced IL-12-induced IFN $\boldsymbol{\gamma}$ secretion. Purity of NK cells isolated by negative selection from peripheral blood of healthy donors was assessed by multicolor flow cytometry including anti-CD56-APC and anti-CD3-PE, -CD19-PE, -CD14-PE, -CD1a-PE, -CD123-PE as lineage exclusion cocktail (A). Purified NK cells were left untreated (NT) or co-cultured with HCMV (MOI 5-10) for 24 and $48 \mathrm{~h}$ in the presence or absence of IL-12 (10 ng/ml) and IL-2 $(200 \mu / \mathrm{ml})$. At $24 \mathrm{~h}$, CD69 expression on NK cells was tested by a double staining with anti-CD56-APC and CD69-PE specific mAbs by flow cytometry (B). IFN $\gamma$ was measured by ELISA in cell-free supernatants harvested at 24 and $48 \mathrm{~h}$ (C). Intracellular IFN $\gamma$ was monitored on NK cells co-cultured for $24 \mathrm{~h}$ with the different stimuli. Brefeldin A was added for the last $5 \mathrm{~h}$ and IFN $\gamma$ staining was analyzed by flow cytometry. Inserts depict the proportion of IFN $\gamma$ positive NK cells (D). In all cases, data correspond to results from a representative donor out of at least three tested. 
Intracellular IFN $\gamma$ staining showed that HCMV moderately increased the frequency of NK cells producing IFN $\gamma$ in response to IL-12. The higher intensity of the IFN $\gamma$ staining in NK cells treated with both stimuli indicated an enhancement or a more sustained IFN $\gamma$ response per cell (Figure 1D). In contrast to the low IFN $\gamma$ secretion detected by ELISA (Figure 1C), a proportion of the NK cells incubated with the virus contained intracellular IFN $\gamma$ (Figure 1D). Differences in IFN $\gamma$ production were not related to NK cell viability that was shown to be similar among the conditions tested, by AnnexinV/Propidium Iodide staining (data not shown).

Since previous experiments included IL-2 $(200 \mu / \mathrm{ml})$, we next assessed whether NK cells would equally respond to HCMV in the absence of IL-2. As shown in Figure 2, HCMV-induced CD69 up-regulation and enhanced IFN $\gamma$ secretion independently of IL-2 signaling; nonetheless, IL-2 magnified the secretion of IFN $\gamma$ in all conditions.

Overall, our data indicated that NK cells could directly recognize HCMV. Sensing of the virus promoted the expression of CD69 and enhanced the secretion of IFN $\gamma$ in response to IL-12, regardless of IL-2 presence.

\section{DIRECT INTERACTION WITH HCMV INCREASES NK CELL DEGRANULATION AGAINST HCMV-INFECTED CELLS}

Degranulation assays were performed to evaluate whether direct recognition of HCMV would also influence NK cell cytotoxicity against HCMV-infected targets. Purified NK cells were incubated with HCMV in the presence or absence of IL-12. After $24 \mathrm{~h}$, cells were harvested, washed to eliminate remaining viral particles and incubated with autologous moDC infected with HCMV as targets or the K562 human leukemia cell line as a positive control. The rate of moDC infection ranged between $40-60 \%$ depending on the donor. CD107a mobilization assays were used to monitor the proportion of NK cells secreting cytolytic granules, As shown in Figures 3A,B NK cells preincubated with HCMV displayed an increased degranulation against HCMV-infected moDC compared to non-treated NK cells, independently of IL-12, while showing similar response against K562 cells (Figure 3C). The NKp46 activating receptor has been previously shown to mediate the recognition of HCMV-infected myelomonocytic cells (Magri et al., 2011; Romo et al., 2011). In order to assess whether sensing of HCMV would modulate the activity of specific NK cell activating receptors, we set up $\mathrm{P} 815$-based redirected assays to analyze the degranulation triggered through NKp46, NKp30, and CD16. Purified NK cells pretreated with HCMV or untreated were confronted to P815 targets coupled to specific mAbs. As shown in Figure 3D, HCMV-primed NK cells tended to display an enhanced NKp46and CD16-mediated degranulation in comparison to mock treated NK cells while comparably responding to NKp30 triggering.

Altogether, these results indicate that sensing of HCMV by NK cells facilitated their activation in response to HCMVinfected moDC.

\section{HCMV RECOGNITION ACTIVATES SEVERAL NK CELL SENSOR} MECHANISMS INVOLVING THE PRODUCTION OF TYPE I IFNs AND TLR2 To further characterize the NK cell response to HCMV, CD69 expression was monitored in freshly purified NK cells cultured

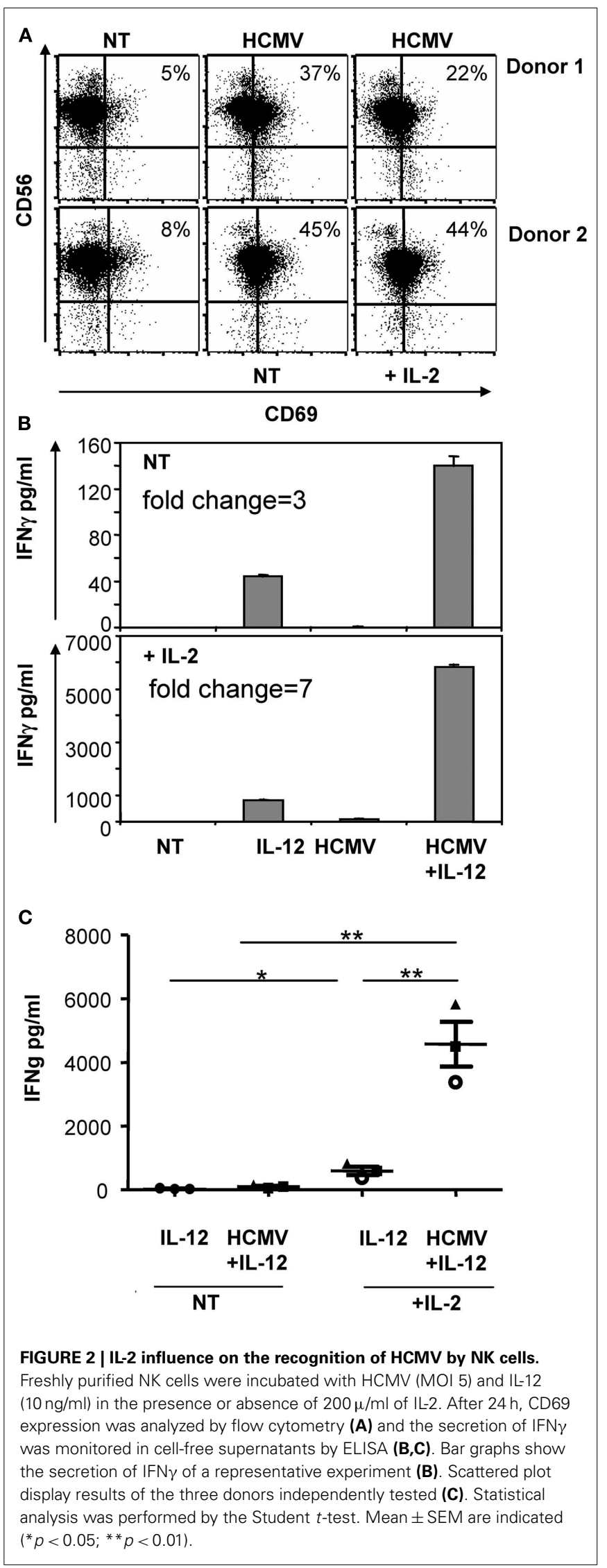



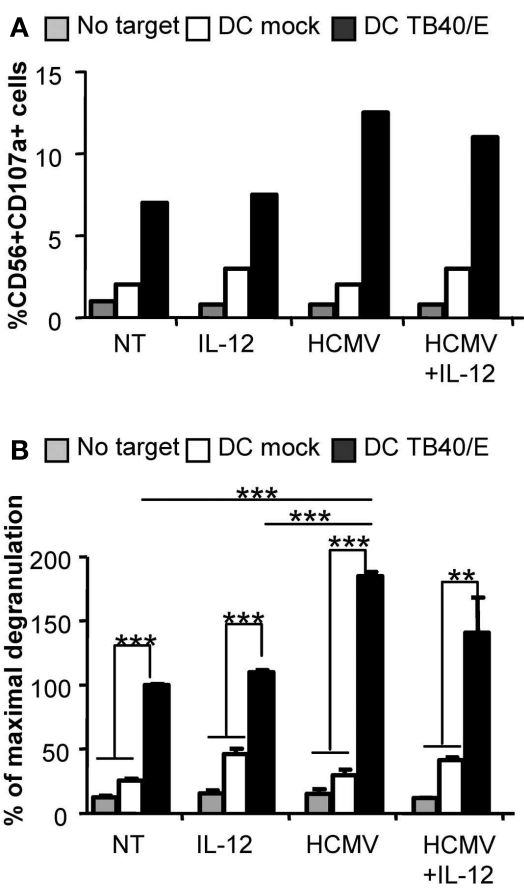

FIGURE 3 | Direct HCMV recognition enhances NK cell degranulation against HCMV-infected moDC. Freshly purified NK cells were incubated alone (NT), or with IL-12 and/or HCMV TB40/E. After $24 \mathrm{~h}$, cells were washed and the degranulation of NK cells was assessed after $5 \mathrm{~h}$ incubation with mock or HCMVTB40/E infected $\operatorname{moDC}(\mathbf{A}, \mathbf{B})$, and K562 (C) (E:T, 4:1). NK cell degranulation was monitored by CD107a staining analyzed by flow cytometry. (A) Bar graphs represent the percent of NK cells positive for CD107a in the absence of target cell (gray bars), in front of mock moDC (empty bars), or HCMV-infected moDC (black bars) from one representative donor. (B) Bar

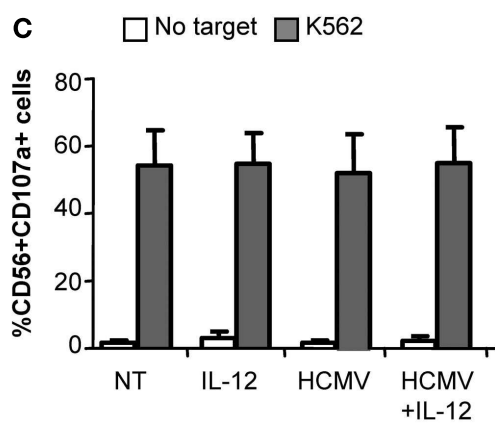

D

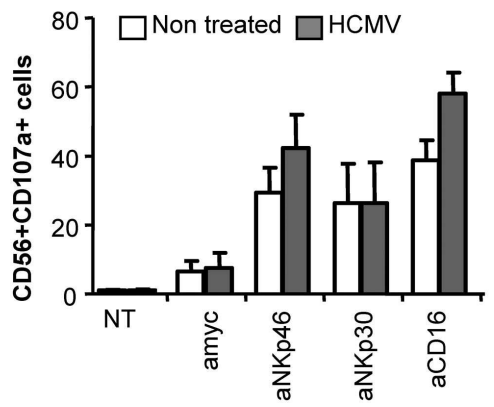

graph displaying the mean \pm SEM of the normalized degranulation. Data in each experiment were normalized to the response of non-treated NK cells incubated with HCMV-infected DC (100\%). Statistical analysis by the Student t-test $\left({ }^{* *} p<0.01 ;{ }^{* *} p<0.0001\right)$ (C) Bar graph showing the mean \pm SEM of the percent in degranulation to K562 of three donors tested (D) Bar graph displaying the mean \pm SEM frequency of CD56+CD107a+ of non-treated (empty bars) or HCMV treated (gray bars) NK cells responding to P815 cells coupled to mAbs specific for NKp46 (Bab281), NKp30 (az20), CD16 (KD1), and anti-myc as control lgG in three independent experiments.

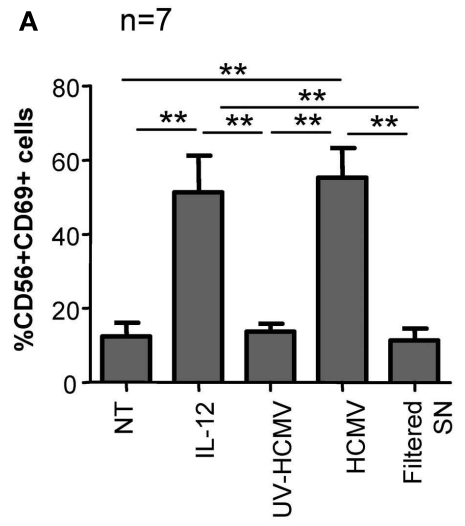

B $n=5$

FIGURE 4 | NK cell activation in response to infective and UV-inactivated HCMV. Freshly purified NK cells were incubated with infective-,

UV-inactivated- HCMV, or filtered viral supernatant in the presence or absence of IL-12 (10 ng/ml). After $24 \mathrm{~h}, \mathrm{CD} 69$ expression was analyzed by two-color

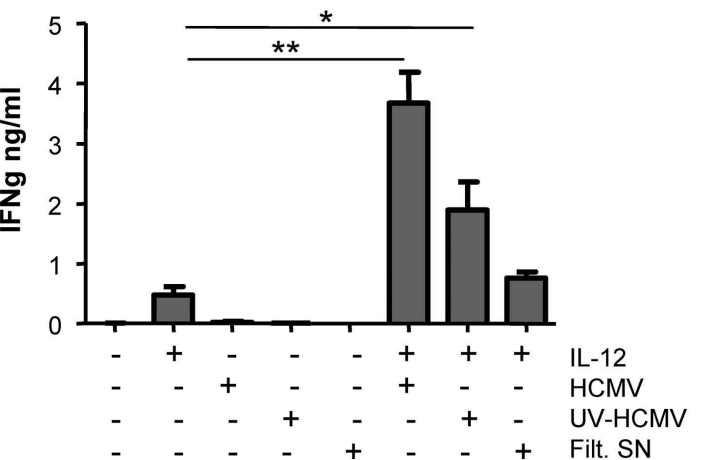

flow cytometry with specific mAbs anti-CD69 and -CD56 (A) and IFN $\gamma$ secretion was measured by ELISA in cell-free supernatants (B). Bar graphs correspond to the mean \pm SEM of the results obtained with the indicated donors. Statistic analysis by the Student $t$-test $\left({ }^{*} p<0.05 ;{ }^{*} p<0.01\right)$. with infective-, UV-inactivated HCMV, and filtered viral supernatant for $24 \mathrm{~h}$. Only infective but not UV-inactivated virus or supernatant devoid of viral particles induced CD69 expression on NK cells (Figure 4A). To assess IFN $\gamma$ secretion, purified NK cells were stimulated in the same conditions in the presence of IL$12(10 \mathrm{ng} / \mathrm{ml})$. Enhanced secretion of IFN $\gamma$ was mostly sustained 
by the infective form of HCMV, UV-inactivated virions showed a partial effect while the filtered viral supernatant did not significantly modify the amount of IFN $\gamma$ secreted in response to IL-12 (Figure 4B). Thus, HCMV-induced NK cell activation was absolutely dependent on the presence of viral particles, ruling out the presence of other pathogen-associated molecular patterns or damage-associated molecular patterns in the virus stock supernatant.

The different response to infective and UV-inactivated virus suggested that HCMV triggered at least two distinct NK cell sensor mechanisms. Since TLR2 is one of the major HCMV sensors, we investigated whether it could be involved in the recognition of this virus by NK cells. Staining of freshly isolated PBMC with anti-TLR2 in combination with anti-CD56 and anti-CD3 showed that TLR2 expression was intracellular in NK cells, being barely detectable on the cell surface. In contrast, monocytes displayed TLR2 at the cell surface (Figure 5A). To test whether the endocytic pathway was involved in HCMV sensing, endosome maturation was blocked by adding bafilomycin A1, an inhibitor of the vacuolar-type $\mathrm{H}+-$-ATPase, along NK cell treatment with HCMV. Bafilomycin A1 prevented the increase in IFN $\gamma$ triggered by both infective and Uv-inactivated virus while keeping unaltered the secretion in response to IL-12 (Figure 5B).

Given that type I IFNs have been previously shown to induce CD69 expression in NK cells (Waddell et al., 2010; Magri et al., 2011), we used blocking mAb for TLR-2 and IFNAR to test their participation in the NK cell response to HCMV. CD69 expression and the secretion of IFN $\gamma$ were analyzed after treating NK cells with HCMV and IL-12 in the presence of blocking reagents. As shown in Figures 6A,B, HCMV-induced up-regulation of CD69 was completely prevented by blocking the type I IFN receptor, while the presence of TLR2 blocking $\mathrm{mAb}$ had a minor effect, comparable to control IgG. In contrast, HCMV-induced secretion of IFN $\gamma$ was partially prevented by both anti-TLR2 and -IFNAR-blocking mAbs (Figure 6C). The expression of CD69 and the secretion of IFN $\gamma$ in NK cells stimulated with IL-12 was comparable in the presence of blocking $\mathrm{mAb}$ (Figures 6A-C).

The analysis of IFN $\gamma$ and IFN $\beta$ mRNA in purified NK cells showed that IL-12 was initially driving the increase in IFN $\gamma$ mRNA $(6 \mathrm{~h})$. After $18 \mathrm{~h}, \mathrm{HCMV}$ enhanced IFN $\gamma$ mRNA levels in both IL12-treated and non-treated NK cells (Figure 7). HCMV but not IL-12 triggered IFN $\beta$ mRNA expression in NK cells, detected at $6 \mathrm{~h}$ and increasing after $18 \mathrm{~h}$ of treatment (Figure 7). IFN $\alpha$ was not detected in the supernatants (data not shown), pointing out the role of IFN $\beta$ in the observed type I IFN-dependent activation of NK cells.

Taken together, our results indicate that NK cell recognition of HCMV is mediated by at least two different sensor mechanisms. Infective HCMV triggers a type I IFN response, likely driven by autocrine IFN $\beta$ production, which induces CD69 surface expression, while TLR2 participates in the recognition of the viral particle promoting IFN $\gamma$ secretion.

\section{DISCUSSION}

To date, the NK cell response to HCMV has been characterized in animal models or in in vitro culture systems that do not allow assessing whether the direct interaction between NK
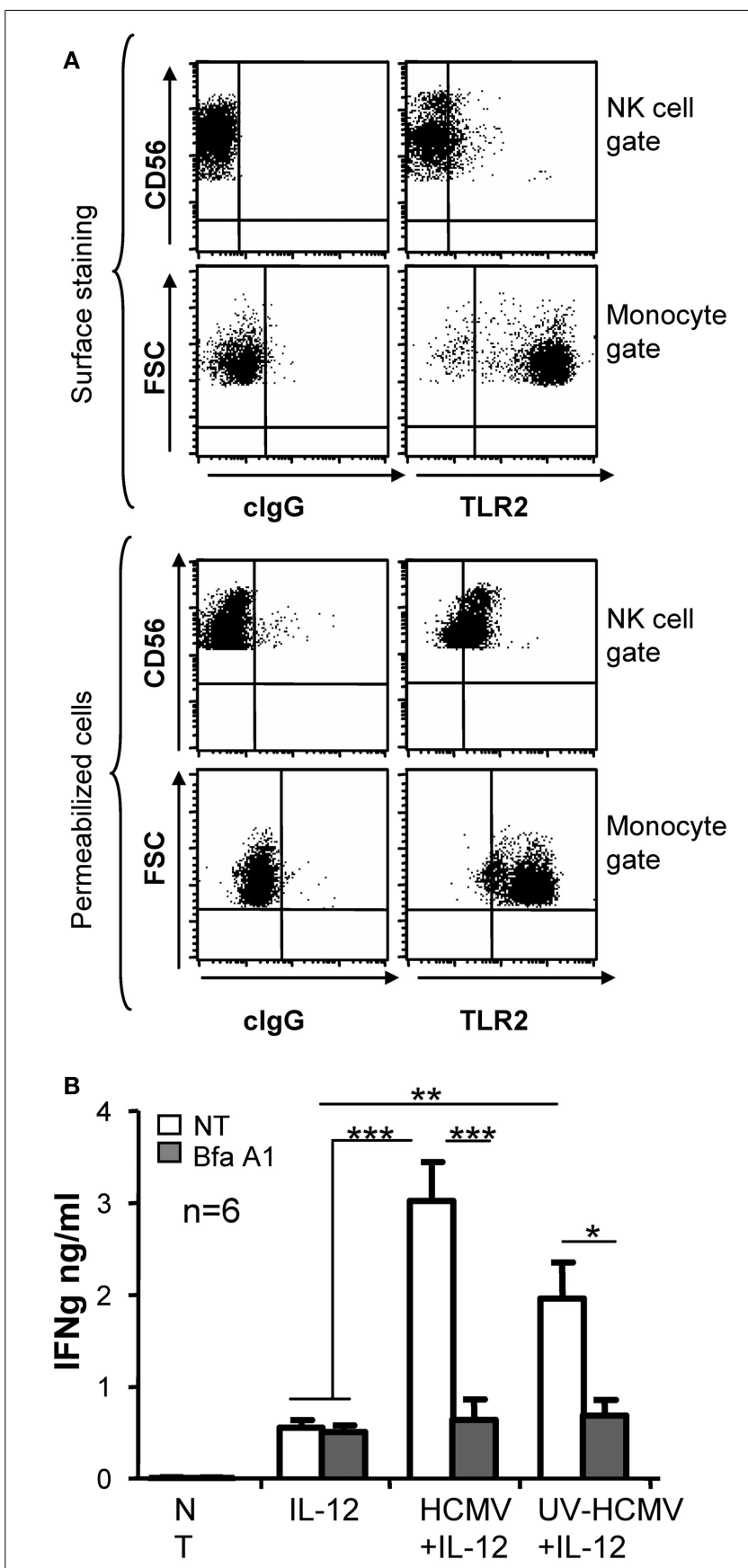

FIGURE 5 | Intracellular TLR2 localization and effect of Bafilomycin A1 treatment in HCMV sensing by NK cells. PBMC samples were analyzed by three color flow cytometry with $m A b$ specific for TLR2 or a control lgG in combination with anti-CD3-PerCP and anti-CD56-APC. For intracellular staining PBMC were fixed and permeabilized prior to the incubation with mAbs. Dot plots display the staining for TLR2 in the NK cell gate (CD56+CD3-) and in monocytes gated by forward and side light scatter. Data correspond to one representative donor out of three analyzed (A). IFN $\gamma$ secretion was measured by ELISA in supernatants from NK cells incubated with IL-12 and infective- or UV-inactivated HCMV, in the presence or absence of Bafilomycin A1 (Bfa A1, $25 \mathrm{nM}$ ). Empty and gray bars correspond to non-treated (NT) and Bfa A1 treated cultures. Bar graph showing the mean \pm SEM of the data obtained from six donors (B). Statistic analysis by the Student $t$-test $\left({ }^{*} p<0.05 ;{ }^{* *} p<0.01 ;{ }^{* * *} p<0.0001\right.$ ). 

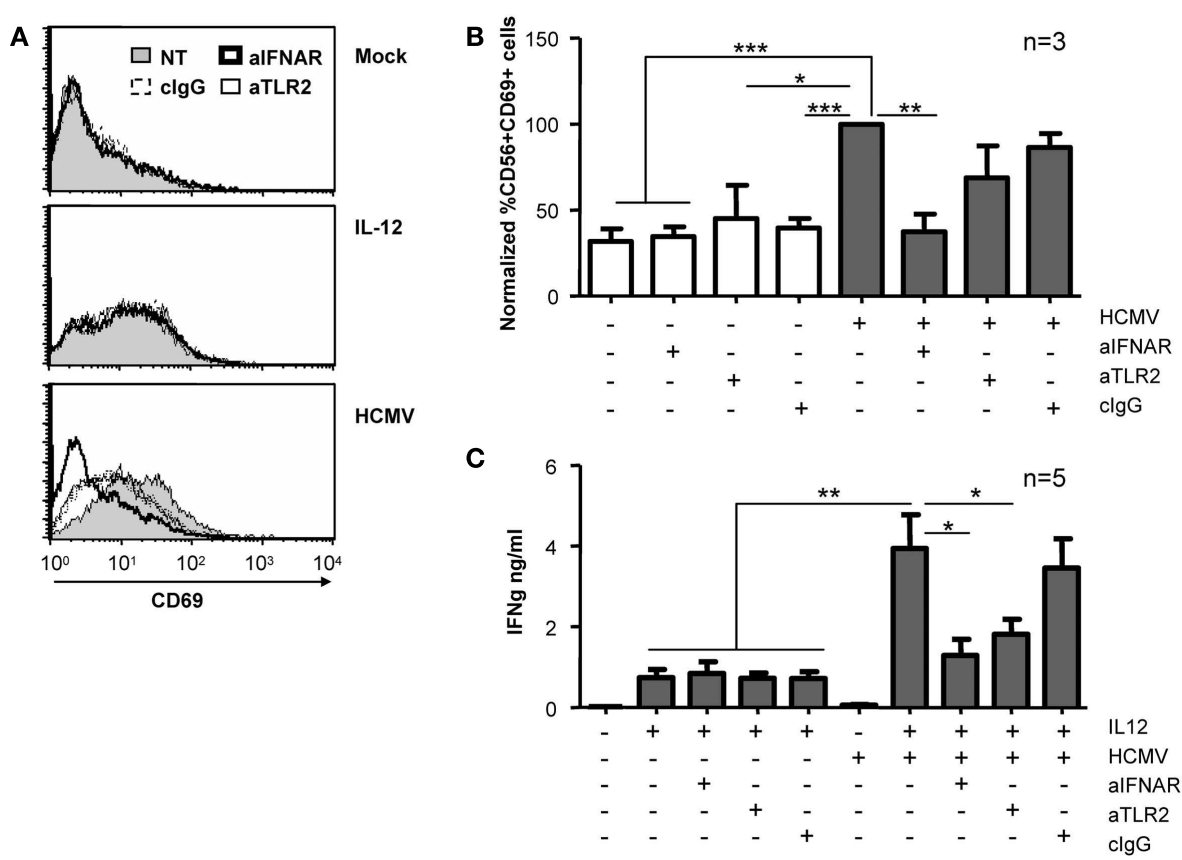

FIGURE 6 | Effect of IFNAR and TLR2 blockade on NK cell activation. Freshly purified NK cells were left untreated or incubated with HCMV and IL-12 in the presence or absence of antagonizing antibodies for TLR2 and IFNAR. CD69 expression (A,B) and IFN $\gamma$ secretion (C) were monitored at $24 \mathrm{~h}$ by flow cytometry and ELISA, respectively. (A) Histograms depict surface CD69 expression on NK cells in the absence of blocking mAbs (NT, gray profiles) or when cultures included anti-IFNAR (bold lines), anti-TLR2 (thin lines), or control lgG (dashed lines). Results from one representative donor are shown. (B) Bar graph showing the mean \pm SEM of the normalized expression of CD69. Data in each experiment were normalized to the CD69 expressed by NK cells exposed to HCMV in the absence of blocking reagents $(100 \%)$. (C) Bars graph displaying the mean \pm SEM of IFN $\gamma$ secretion in five donors. Statistic analysis by the Student $t$-test $\left({ }^{*} p<0.05 ;{ }^{* *} p<0.01 ;{ }^{* *} p<0.0001\right)$. cells and HCMV may influence the anti-viral response. Given the fact that NK cells express functional PRRs, we developed an experimental system to examine the capacity of $\mathrm{NK}$ cells to sense HCMV. The data demonstrate that direct HCMV recognition results in TLR2 activation and the production of type I IFNs leading to the priming of NK cells as evidenced by (i) induced expression of the CD69 activation marker, (ii) enhanced secretion of IFN $\gamma$ and, (iii) increased degranulation against HCMV-infected moDC.

The interaction of NK cells with HCMV triggered at least two sensor mechanisms distinguished by the response to infective and UV-inactivated viral particles. Recognition of infective HCMV-induced the expression of CD69 in CD56 ${ }^{\text {dim }}$ NK cells. In agreement with previous reports (Waddell et al., 2010; Magri et al., 2011), IFNAR-blocking mAbs prevented the expression of this early activation marker, indicating that HCMV recognition by resting NK cells triggers the production of type I IFNs. The expression of IFN $\beta$ mRNA supported this cytokine as the likely candidate for the autocrine effect. Type I IFN responses in MCMV infection partially depend on TLR2 activation (Szomolanyi-Tsuda et al., 2006; Barbalat et al., 2009). In our experimental system, the inefficacy of anti-TLR2 $\mathrm{mAb}$ in preventing HCMV-induced CD69 up-regulation together with the failure of $\mathrm{UV}$-inactivated virions to induce CD69 expression, argued against the involvement of any TLR in the type I IFN response of NK cells to HCMV. The requirement of infective virions for CD69 up-regulation suggests that HCMV may enter into NK cells, initiating its transcriptional program and thus, allowing the activation of cytosolic PRRs. Cellular receptors such as heparan sulfate proteoglycans and the $\beta 1$-integrin VLA-6 found in resting NK cells (Perez-Villar et al., 1996) could, theoretically, mediate the entry of HCMV (Compton, 2004). Yet, according with the resistance of lymphocytes to HCMV productive infection, we did not detect nuclear accumulation of the immediate early HCMV proteins IE-1/IE-2 in NK cells co-cultured with infective virions (data not shown; Rice et al., 1984; Nowlin et al., 1991). Our results do not allow to pinpoint which cytosolic sensor/s are involved in the HCMV-dependent IFN $\beta$ response but likely candidates are Mda5 or RIG-1, reported to be expressed in NK cells and to induce IFN $\beta$ secretion in response to polyI:C, a synthetic analog to viral dsRNA (Duluc et al., 2009; Perrot et al., 2010). Whether any resting NK cell is susceptible to HCMV entry or whether a particular NK cell subset supports the IFN $\beta$ response to HCMV, deserves further attention.

On the other hand, simultaneous addition of IL-12 and HCMV to NK cells, promoted a substantial IFN $\gamma$ secretion, exceeding the effect of IL-12 alone. In this case, antagonistic anti-TLR2 mAbs partially blocked the synergism, indicating the involvement of this TLR in the recognition of HCMV by NK cells. Indeed, HCMV envelope glycoproteins $\mathrm{gB}$ and $\mathrm{gH}$ bind TLR2, triggering NF-kB activation in other cell types (Boehme et al., 2006). The fact that UV-inactivated viral particles also enhanced IL-12-induced IFN $\gamma$ 
secretion further supports the idea that structural virion component/s are being recognized by NK cells. Although, TLR2 was barely detected on the NK cell surface by flow cytometry, intracellular TLR2 showed a consistent staining, agreeing with a previous report (Eriksson et al., 2006). Consistent with the likely TLR2 location in NK cell endosomes, an inhibitor of endosomal maturation (i.e., Bafilomycin A1) prevented HCMV-dependent IFN $\gamma$ secretion. As TLR2 recognizes hydrophobic PAMPs, it is possible that acidification of the endocytic pathway would allow hindered peptides in $\mathrm{gB}$ to become exposed and visible to TLR2. Considering the specialized role of NK cells in the control of viral infections, it is tempting to speculate that intracellular TLR2 could serve as a mechanism to ensure its activation in response to intracellular pathogens. In this line, TLR2 has also been involved in the recognition of hepatitis $C$ virus, lymphocytic choriomeningitis virus, measles virus, vaccinia virus, herpes simplex virus, and $M$. bovis by NK cells and other cell types (Bieback et al., 2002; Chang et al., 2007; Zhu et al., 2007; Marcenaro et al., 2008; Martinez et al., 2010; Leoni et al., 2012).

Human Cytomegalovirus recognition by NK cells resulted in the priming of at least two important anti-viral effector mechanisms: IFN $\gamma$ secretion and cytotoxicity against infected cells. Both TLR2 and type I IFNs enhanced the secretion of IFN $\gamma$, as indirectly shown by the partial blockade with antagonistic mAbs for TLR2 and IFNAR, respectively. Engagement of TLR2 may enhance IFN $\gamma$ secretion through the activation of NF-kB and Ik-Bzeta, similarly to IL-18R activation (Akira et al., 2006). The late increase of HCMV-dependent IFN $\gamma$ mRNA levels is reminiscent of the kinetics of IFN $\gamma$ production upon IL-12+IL-18 stimulation in NK cells (Miyake et al., 2010; Kannan et al., 2011). Of note, two genetic studies have shown that specific TLR2 polymorphisms condition the probability to develop CMV disease in transplant recipients (Kijpittayarit et al., 2007; Kang et al., 2012). Assessing whether TLR2 polymorphisms could explain the important interindividual variability in the magnitude of IFN $\gamma$ secreted by NK cells in response to HCMV deserves attention. On the other hand, the partial blockade exerted by IFNAR-blocking mAb supports the participation of autocrine IFN $\beta$ in the secretion of IFN $\gamma$. Signaling through IFNAR could directly cooperate with IL-12 (Duluc et al., 2009) or indirectly support IFN $\gamma$ secretion by promoting TLR expression (Miettinen et al., 2001).

Natural killer cell interaction with infective HCMV also facilitated the subsequent recognition and degranulation against infected targets. This effect was independent of IL-12 and presumably related to the autocrine effect of type I IFNs induced by the virus. The requirement for type I IFNs stimulation on NK cells for the development of efficient cytotoxic responses has been previously appreciated (Martinez et al., 2008), however, the underlying mechanism remains largely unaddressed. It is known that type I IFNs increase granzyme B, perforin, IFN $\gamma, \mathrm{TNF} \alpha$, and NKG2A mRNA levels (Mori et al., 1998; Martinez et al., 2008), suppressing two miRNA (miR-378 and miR30e) that negatively regulate perforin and granzyme B expression in resting NK cells (Wang et al., 2012). Redirected degranulation assays suggested that NK cell priming by HCMV enhanced NKp46-mediated activation, most probably participating in the enhanced NK cell degranulation against infected moDC, according to previous reports (Magri et al.,

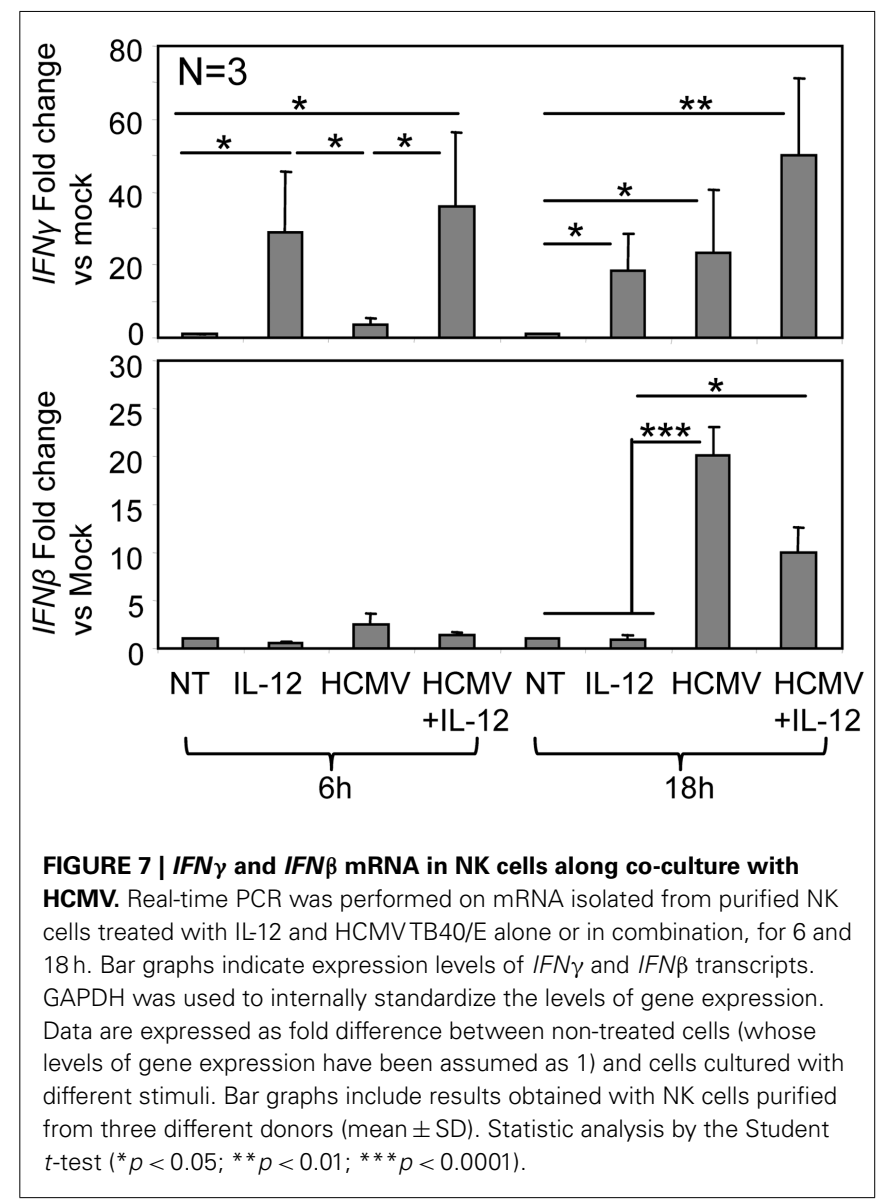

2011; Romo et al., 2011). Whether the increase in the activity of these particular activating receptors occurs as a consequence of type I IFN signaling or by an alternative pathway triggered by HCMV deserves further attention.

\section{CONCLUSION}

Physiologically, NK cells present in the inflammatory infiltrates of HCMV active replication sites would have the chance of directly encounter viral particles. Our data shows that the direct recognition of a complex pathogen such as HCMV activates complementary PRRs leading to the autonomous priming of NK cell effector functions, a mechanism likely contributing to the anti-viral response.

\section{ACKNOWLEDGMENTS}

We thank Dr. Carsten Kirschning for generously providing the blocking mAb anti-TLR2 and Dr. Daniela Pende for providing mAbs for NKp30 and NKp46. We are grateful to Esther Menoyo for collaborating in the obtention of blood samples, Dr. Oscar Fornas for advice in flow cytometry and to all volunteer blood donors. This work was supported by grants from Plan Nacional de I + D (SAF2010-22153-C03), and EU SUDOE program (SOE2/P1/E341). Aura Muntasell is supported by Asociación Española Contra el Cáncer (AECC), Andrea Vera is supported by Red HERACLES (Instituto de Salut Carlos III). 


\section{REFERENCES}

Akira, S., Uematsu, S., and Takeuchi, O. (2006). Pathogen recognition and innate immunity. Cell 124, 783-801.

Alter, G., Malenfant, J. M., and Altfeld, M. (2004). CD107a as a functional marker for the identification of natural killer cell activity. J. Immunol. Methods 294, 15-22.

Athie-Morales, V., O'Connor, G. M., and Gardiner, C. M. (2008). Activation of human NK cells by the bacterial pathogen-associated molecular pattern muramyl dipeptide. J. Immunol. 180, 4082-4089.

Barbalat, R., Lau, L., Locksley, R. M., and Barton, G. M. (2009). Tolllike receptor 2 on inflammatory monocytes induces type I interferon in response to viral but not bacterial ligands. Nat. Immunol. 10, 1200-1207.

Becker, I., Salaiza, N., Aguirre, M., Delgado, J., Carrillo-Carrasco, N., Kobeh, L. G., et al. (2003). Leishmania lipophosphoglycan (LPG) activates NK cells through toll-like receptor-2. Mol. Biochem. Parasitol. 130, 65-74.

Bieback, K., Lien, E., Klagge, I. M., Avota, E., Schneider-Schaulies, J., Duprex, W. P., et al. (2002). Hemagglutinin protein of wild-type measles virus activates toll-like receptor 2 signaling. J. Virol. 76, 8729-8736.

Biron, C. A., Byron, K. S., and Sullivan, J. L. (1989). Severe herpesvirus infections in an adolescent without natural killer cells. N. Engl. J. Med. 320, 1731-1735.

Biron, C. A., Nguyen, K. B., Pien, G. C., Cousens, L. P., and SalazarMather, T. P. (1999). Natural killer cells in antiviral defense: function and regulation by innate cytokines. Annu. Rev. Immunol. 17, 189-220.

Boehme, K. W., Guerrero, M., and Compton, T. (2006). Human cytomegalovirus envelope glycoproteins $\mathrm{B}$ and $\mathrm{H}$ are necessary for TLR2 activation in permissive cells. J. Immunol. 177, 7094-7102.

Carvalho, A., Cunha, C., Carotti, A., Aloisi, T., Guarrera, O., Di Ianni, M., et al. (2009). Polymorphisms in Tolllike receptor genes and susceptibility to infections in allogeneic stem cell transplantation. Exp. Hematol. 37, 1022-1029.

Chalifour, A., Jeannin, P., Gauchat, J. F., Blaecke, A., Malissard, M., N'Guyen, T., et al. (2004). Direct bacterial protein PAMP recognition by human NK cells involves TLRs and triggers alpha-defensin production. Blood 104, 1778-1783.
Chang, S., Dolganiuc, A., and Szabo, G. (2007). Toll-like receptors 1 and 6 are involved in TLR2-mediated macrophage activation by hepatitis C virus core and NS3 proteins. $J$. Leukoc. Biol. 82, 479-487.

Compton, T. (2004). Receptors and immune sensors: the complex entry path of human cytomegalovirus. Trends Cell Biol. 14, 5-8.

DeFilippis, V. R., Sali, T., Alvarado, D., White, L., Bresnahan, W., and Fruh, K. J. (2010). Activation of the interferon response by human cytomegalovirus occurs via cytoplasmic double-stranded DNA but not glycoprotein B. J. Virol. 84, 8913-8925.

Duluc, D., Tan, F., Scotet, M., Blanchard, S., Fremaux, I., Garo, E., et al. (2009). PolyI:C plus IL-2 or IL-12 induce IFN-gamma production by human NK cells via autocrine IFN-beta. Eur. J. Immunol. 39, 2877-2884.

Eriksson, M., Meadows, S. K., Basu, S., Mselle, T. F., Wira, C. R., and Sentman, C. L. (2006). TLRs mediate IFN-gamma production by human uterine NK cells in endometrium. J. Immunol. 176, 6219-6224.

Girart, M. V., Fuertes, M. B., Domaica, C. I., Rossi, L. E., and Zwirner, N. W. (2007). Engagement of TLR3, TLR7, and NKG2D regulate IFNgamma secretion but not NKG2Dmediated cytotoxicity by human NK cells stimulated with suboptimal doses of IL-12. J. Immunol. 179, 3472-3479.

Gorski, K. S., Waller, E. L., BjorntonSeverson, J., Hanten, J. A., Riter, C. L., Kieper, W. C., et al. (2006). Distinct indirect pathways govern human NK-cell activation by TLR7 and TLR-8 agonists. Int. Immunol. 18, 1115-1126.

Hart, O. M., Athie-Morales, V., O'Connor, G. M., and Gardiner, C. M. (2005). TLR7/8-mediated activation of human NK cells results in accessory cell-dependent IFNgamma production. J. Immunol. 175, 1636-1642.

Hornung, V., Rothenfusser, S., Britsch, S., Krug, A., Jahrsdorfer, B., Giese, T., et al. (2002). Quantitative expression of toll-like receptor 1-10 mRNA in cellular subsets of human peripheral blood mononuclear cells and sensitivity to $\mathrm{CpG}$ oligodeoxynucleotides. J. Immunol. 168, 4531-4537.

Janson, P. C., Marits, P., Thorn, M., Ohlsson, R., and Winqvist, O. (2008). CpG methylation of the IFNG gene as a mechanism to induce immunosuppression in tumor-infiltrating lymphocytes. J. Immunol. 181, 2878-2886.

Kang, S. H., Abdel-Massih, R. C., Brown, R. A., Dierkhising, R. A., Kremers, W. K., and Razonable, R. R. (2012). Homozygosity for the toll-like receptor 2 R753Q singlenucleotide polymorphism is a risk factor for cytomegalovirus disease after liver transplantation. J. Infect. Dis. 205, 639-646.

Kannan, Y., Yu, J., Raices, R. M. Seshadri, S., Wei, M., Caligiuri, M. A., et al. (2011). IkappaBzeta augments IL-12- and IL-18-mediated IFN-gamma production in human NK cells. Blood 117, 2855-2863.

Kijpittayarit, S., Eid, A. J., Brown, R. A., Paya, C. V., and Razonable, R. R. (2007). Relationship between Tolllike receptor 2 polymorphism and cytomegalovirus disease after liver transplantation. Clin. Infect. Dis. 44, 1315-1320.

Krug, A., French, A. R., Barchet, W., Fischer, J. A., Dzionek, A., Pingel, J. T., et al. (2004). TLR9-dependent recognition of MCMV by IPC and DC generates coordinated cytokine responses that activate antiviral NK cell function. Immunity 21, 107-119.

Lanier, L. L. (2008). Up on the tightrope: natural killer cell activation and inhibition. Nat. Immunol. 9, 495-502.

Leoni, V., Gianni, T., Salvioli, S., and Campadelli-Fiume, G. (2012). Herpes simplex virus glycoproteins $\mathrm{gH} / \mathrm{gL}$ and $\mathrm{gB}$ bind Toll-like receptor 2 , and soluble $\mathrm{gH} / \mathrm{gL}$ is sufficient to activate NF-kappaB. J. Virol. 86 , 6555-6562.

Magri, G., Muntasell, A., Romo, N. Saez-Borderias, A., Pende, D., Geraghty, D. E., et al. (2011). NKp46 and DNAM-1 NK-cell receptors drive the response to human cytomegalovirus-infected myeloid dendritic cells overcoming viral immune evasion strategies, Blood 117, 848-856.

Marcenaro, E., Ferranti, B., Falco, M. Moretta, L., and Moretta, A. (2008). Human NK cells directly recognize Mycobacterium bovis via TLR2 and acquire the ability to kill monocytederived DC. Int. Immunol. 20 1155-1167.

Marr, K. J., Jones, G. J., Zheng, C., Huston, S. M., Timm-McCann, M., Islam, A., et al. (2009). Cryptococcus neoformans directly stimulates perforin production and rearms NK cells for enhanced anticryptococcal microbicidal activity. Infect. Immun. 77, 2436-2446.

Martinez, J., Huang, X., and Yang, Y. (2008). Direct action of type I IFN on NK cells is required for their activation in response to vaccinia viral infection in vivo. J. Immunol. 180, 1592-1597.

Martinez, J., Huang, X., and Yang, Y. (2010). Direct TLR2 signaling is critical for NK cell activation and function in response to vaccinia viral infection. PLoS Pathog. 6:e1000811. doi:10.1371/journal.ppat.1000811

Meng, G., Rutz, M., Schiemann, M., Metzger, J., Grabiec, A., Schwandner, R., et al. (2004). Antagonistic antibody prevents toll-like receptor 2-driven lethal shock-like syndromes. J. Clin. Invest. 113, 1473-1481.

Miettinen, M., Sareneva, T., Julkunen, I., and Matikainen, S. (2001). IFNs activate toll-like receptor gene expression in viral infections. Genes Immun. 2, 349-355.

Miyake, T., Satoh, T., Kato, H., Matsushita, K., Kumagai, Y., Vandenbon, A., et al. (2010). IkappaBzeta is essential for natural killer cell activation in response to IL-12 and IL18. Proc. Natl. Acad. Sci. U.S.A. 107, 17680-17685.

Mocarski, E. S., and Courcelle, C. T. (2001). "Cytomegaloviruses and their replication," in Fields Virol $o g y$, eds D. M. Knipe, P. M. Howley, D. E. Griffin, and R. A. Lamb (Philadelphia: Lippincott, Williams and Wilkins), 2629-2673.

Mori, S., Jewett, A., Cavalcanti, M., Murakami-Mori, K., Nakamura, S., and Bonavida, B. (1998). Differential regulation of human NK cellassociated gene expression following activation by IL-2, IFN-alpha and PMA/ionomycin. Int. J. Oncol. 12, 1165-1170.

Muntasell, A., Magri, G., Pende, D. Angulo, A., and Lopez-Botet, M. (2010). Inhibition of NKG2D expression in NK cells by cytokines secreted in response to human cytomegalovirus infection. Blood 115, 5170-5179.

Nowlin, D. M., Cooper, N. R., and Compton, T. (1991). Expression of a human cytomegalovirus receptor correlates with infectibility of cells. J. Virol. 65, 3114-3121.

Orange, J. S., and Ballas, Z. K. (2006). Natural killer cells in human health and disease. Clin. Immunol. 118, 1-10.

Perez-Villar, J. J., Melero, I., Gismondi, A., Santoni, A., and Lopez-Botet, M. (1996). Functional analysis of alpha 1 beta 1 integrin in human natural killer cells. Eur. J. Immunol. 26, 2023-2029.

Perrot, I., Deauvieau, F., Massacrier, C., Hughes, N., Garrone, P., Durand, 
I., et al. (2010). TLR3 and Rig-like receptor on myeloid dendritic cells and Rig-like receptor on human NK cells are both mandatory for production of IFN-gamma in response to double-stranded RNA. J. Immunol. 185, 2080-2088.

Rathinam, V. A., Jiang, Z., Waggoner, S. N., Sharma, S., Cole, L. E., Waggoner, L., et al. (2010). The AIM2 inflammasome is essential for host defense against cytosolic bacteria and DNA viruses. Nat. Immunol. 11, 395-402.

Rice, G. P., Schrier, R. D., and Oldstone, M. B. (1984). Cytomegalovirus infects human lymphocytes and monocytes: virus expression is restricted to immediate-early gene products. Proc. Natl. Acad. Sci. U.S.A. 81, 6134-6138.

Roda, J. M., Parihar, R., and Carson, W. E. III. (2005). CpG-containing oligodeoxynucleotides act through TLR9 to enhance the NK cell cytokine response to antibodycoated tumor cells. J. Immunol. 175 , 1619-1627.

Romo, N., Magri, G., Muntasell, A., Heredia, G., Baia, D., Angulo, A., et al. (2011). Natural killer cell-mediated response to human cytomegalovirus-infected macrophages is modulated by their functional polarization. J. Leukoc. Biol. 90, 717-726.

Sinzger, C., Schmidt, K., Knapp, J., Kahl, M., Beck, R., Waldman, J., et al. (1999). Modification of human cytomegalovirus tropism through propagation in vitro is associated with changes in the viral genome. J. Gen. Virol. 80(Pt 11), 2867-2877.

Sivori, S., Falco, M., Della, C. M., Carlomagno, S., Vitale, M., Moretta, L., et al. (2004). CpG and doublestranded RNA trigger human NK cells by Toll-like receptors: induction of cytokine release and cytotoxicity against tumors and dendritic cells. Proc. Natl. Acad. Sci. U.S.A. 101, 10116-10121.

Szomolanyi-Tsuda, E., Liang, X., Welsh, R. M., Kurt-Jones, E. A., and Finberg, R. W. (2006). Role for TLR2 in NK cell-mediated control of murine cytomegalovirus in vivo. J. Virol. 80, 4286-4291.

Tabeta, K., Georgel, P., Janssen, E., $\mathrm{Du}, \mathrm{X}$. , Hoebe, K., Crozat, K., et al. (2004). Toll-like receptors 9 and 3 as essential components of innate immune defense against mouse cytomegalovirus infection. Proc. Natl. Acad. Sci. U.S.A. 101, 3516-3521.

Waddell, S. J., Popper, S. J., Rubins, K. H., Griffiths, M. J., Brown, P. O. Levin, M., et al. (2010). Dissecting interferon-induced transcriptional programs in human peripheral blood cells. PLoS ONE 5:e9753. doi:10.1371/journal.pone.0009753

Wang, P., Gu, Y., Zhang, Q., Han, Y., Hou, J., Lin, L., et al. (2012). Identification of resting and type I IFN-activated human NK cell miRNomes reveals microRNA-378 and microRNA-30e as negative regulators of NK cell cytotoxicity. $J$. Immunol. 189, 211-221.

Zhu, J., Martinez, J., Huang, X., and Yang, Y. (2007). Innate immunity against vaccinia virus is mediated by TLR 2 and requires TLRindependent production of IFNbeta. Blood 109, 619-625.

Zucchini, N., Bessou, G., Traub, S., Robbins, S. H., Uematsu, S., Akira, S., et al. (2008). Cutting edge: overlapping functions of TLR7 and TLR9 for innate defense against a herpesvirus infection. J. Immunol. 180, 5799-5803.
Conflict of Interest Statement: The authors declare that the research was conducted in the absence of any commercial or financial relationships that could be construed as a potential conflict of interest.

Received: 31 October 2012; accepted: 04 February 2013; published online: 21 February 2013.

Citation: Muntasell A, Costa-Garcia M, Vera A, Marina-Garcia N, Kirschning CJ and López-Botet M (2013) Priming of NK cell anti-viral effector mechanisms by direct recognition of human cytomegalovirus. Front. Immun. 4:40. doi: 10.3389/fimmu.2013.00040

This article was submitted to Frontiers in NK Cell Biology, a specialty of Frontier in Immunology.

Copyright (C) 2013 Muntasell, CostaGarcia, Vera, Marina-Garcia, Kirschning and López-Botet. This is an openaccess article distributed under the term of the Creative Commons Attribution License, which permits use, distribution and reproduction in other forums, provided the original authors and source are credited and subject to any copyright notices concerning any third-party graphics etc. 